\title{
Do monitoramento do correio eletrônico na relação de emprego
}

\author{
Mariane Santos Fernandes ${ }^{1}$
}

Prof. Dr. Lourival José de Oliveira ${ }^{2}$

\section{Resumo}

\begin{abstract}
Pesquisou-se sobre o uso do correio eletrônico e o seu monitoramento nas relações de trabalho, como situações não previstas e delineadas pela legislação trabalhista pátria. Equiparou-se a correspondência eletrônica à postal, com vistas à assegurar proteção constitucional à inviolabilidade das comunicações e respeito à intimidade e privacidade. Analisou-se a possibilidade patronal de monitoramento do correio eletrônico e as distintas correntes que tratam desse assunto. Concluiu-se pela necessidade de serem estabelecidas normas referentes ao monitoramento do correio eletrônico no Brasil, sugerindo-se propostas para a costrução de uma política intraempresarial capaz de regulamnetar o uso desse intrumento.
\end{abstract}

Palavras-Chave: Correio eletrônico; Direito à intimidade, Inviolabilidade das comunicações, Monitoramento na relação de emprego; Propriedade privada.

\section{Introdução}

O elevado grau de desenvolvimento tecnológico alcançado pelo homem vem alterando a estrutura social e econômica em que se vive. O uso da informatização no ambiente de trabalho, fomentando o desenvolvimento das atividades e da produção, é cada vez maior, refletindo, muitas vezes, situações inusitadas ao direito.

Dessa forma é a utilização da correspondência eletrônica nas relações de trabalho, instrumento de comunicação dotado de inúmeras benesses ao empregador que vem, paulatinamente, substituindo as correspondências dantes usuais, e cuja normatização, a respeito do uso e da possibilidade de monitoramento, não se encontra consolidada em nosso ordenamento jurídico.

Seria possível a equiparação de tais mensagens às correspondências postais? Em assim sendo, o controle patronal sobre as mesmas, uma vez acessadas através de equipamentos disponibilizados unicamente para fins profissionais, colidiria com os Princípios Constitucionais protetores da intimidade individual e da inviolabilidade das comunicações?

Acadêmica do 5o ano matutino do curso de Direito da Universidade Estadual de Londrina.

Doutor em Direito (PUC-SP); professor adjunto da Universidade Estadual de Londrina; professor da UNOPAR; professor da FACCAR; professor da UNIMAR. 
Poderia o empregador valer-se do Princípio da Propriedade Privada dos equipamentos disponibilizados para vasculhar as correspondências?

Faz-se necessário, neste estudo, apontar a ingerência da tecnologia no ambiente de trabalho, analisar o correio eletrônico e, assim, assumir uma posição adequada no que toca à viabilidade do monitoramento.

\section{Da utilização da informática no ambiente de trabalho}

Atualmente, e cada vez mais, o ambiente de trabalho é diferente daquele em que as normas trabalhistas foram criadas. As novas tecnologias desenvolvidas são introduzidas nesse ambiente em grande velocidade, de acordo com as necessidades sociais e aspirações econômicas. Propiciam inúmeras facilidades ao homem, em face da necessidade de maior produtividade e eficiência no cotidiano de seu trabalho.

Sendo o Direito reflexo da sociedade é certo que está condicionado a acompanhar essa evolução. Árdua tarefa para seus estudiosos e legisladores é fazê-la com a mesma rapidez. Toda norma é criada com um propósito, baseando-se num fato concreto ou abstrato, que pode vir a acontecer. Ocorre que, impossível ao ser humano prever e, assim, legislar sobre todos os tipos de situações e comportamentos. A realidade apresenta problemas que não passaram pelas idéias do legislador.

\subsection{Dos reflexos da tecnologia no ambiente de trabalho}

Depara-se, então, com o grande reflexo da tecnologia no Direito do Trabalho: necessidade da flexibilização das normas trabalhistas. Fenômeno de atualização deste ramo, que deve acontecer de modo a atender aos princípios constitucionais da valorização do trabalho, da dignidade da pessoa humana, da produção da justiça social, tais como preconiza os art. 170, CF: "a ordem econômica, fundada na valorização do trabalho humano e na livre iniciativa, tem por fim, assegurar a todos existência digna (...)" e 193 da CF: "A ordem social tem como base o primado do trabalho, e como objetivo o bem estar e a justiça sociais".

No entender de Antônio Álvares da Silva (2002, p. 85), “O esforço há de ser em certa direção: construir um Direito do Trabalho flexível, que se adapte às necessidades dos novos tempos, mas que também, por outro lado, não prejudique o trabalhador". 
Baseando-se, ainda, nos conceitos de José Martins Catharino (2003, p. 124) tem-se que:

\begin{abstract}
Em um sentido amplo, a flexibilização seria uma modalidade de transformação das normas jurídicas afim de que possam atender às exigências oriundas da economia', e que, 'Uma concepção restritiva entende a flexibilização como uma adequação da ordem jurídica trabalhista, em face das modificações ocorridas na esfera econômica e que se refletem nas relações entre trabalho e capital.
\end{abstract}

Dessa maneira, trata-se de um mecanismo de ajuste do direto à realidade social.

O uso do aparato eletrônico é assunto de grande enfoque neste sentido, ao passo que carece de legislação apta a regulamentar com eficácia e capaz de abranger todas as situações proporcionadas. Toma-se, como exemplo, o uso do correio eletrônico no ambiente de trabalho e seus meandros na relação de emprego. Situação de recente atenção para o ramo justrabalhista, e que perfaz-se objeto imediato do presente estudo, esmiuçando-se, em tese, sua utilização, a possibilidade do seu monitoramento, abordando distintas teorias, e as derivadas implicações na relação empregatícia. Porém, para que se possa abordá-las de maneira mais apropriada é essencial a análise do correio eletrônico como meio de comunicação.

\title{
2.2 Do correio eletrônico
}

A ferramenta dita email é uma forma de transmissão de conteúdos à distância através de uma rede de comunicações, acessada por um computador, a internet. Entendida, nos dizeres de Ana Amélia Menna Barreto de Castro Ferreira (2003, p. 2), "como uma rede pública de zona de dados, dotada de estrutura aberta, descentralizada, naturalmente desregulamentada e com características próprias: agilidade, independência, anonimato e liberdade de expressão".

Consiste, o correio eletrônico, no envio e recebimento de mensagens de uma caixa postal à outra em tempo quase instantâneo. As mensagens são enviadas para um endereço virtual e depositadas nessa caixa eletrônica ou e-mail.

Mario Antonio Lobato de Paiva o caracteriza, nas palavras de Montero Navarro (2002, p. 25), como: 
Um meio eletrônico (utiliza meios eletrônicos de gestão e transporte), assíncrono (não necessita sincronia de envio e recepção), ubíquo (permite seu acesso em diferentes lugares), digital (utiliza informação digitalizada) e informático (tem estreita relação com as tecnologias de informação).

O correio eletrônico tem sido amplamente utilizado tanto para assuntos pessoais como profissionais. Isso ocorre devido ao fato de apresentar certas vantagens em relação aos meios de correspondências convencionais, seja cartas, cartões postais, telegramas, fax. Características tais como a facilidade de manuseio, rapidez na movimentação, baixo custo de manutenção, confiabilidade no envio e recebimento, uma vez que as falhas na transmissão são, usualmente, comunicadas aos usuários, levam, cada vez mais, à sua utilização.

Cumpre mencionar que o indiscriminado uso desse meio de comunicação, inclusive no ambiente de trabalho, dá margem à calorosas discussões a respeito de sua natureza jurídica. Parte majoritária dos doutrinadores inclinados no assunto, na falta de legislação no que tange a internet no Brasil, atualmente, equiparam-no à correspondência postal, ressalvando certas especialidades.

São as palavras de Mário Antônio Lobato de Paiva (2002, p. 29) a esse respeito:

Apesar de não haver dúvida que o correio eletrônico e o correio postal têm a mesma natureza, ou seja, de correspondência, ressalvando suas peculiaridades, encontramos, em doutrina e decisão judicial, posicionamentos divergentes.

Entende-se que as diferenças entre as correspondências física e virtual não devem ser consideradas de maneira radical, uma vez que, apesar de suas peculiaridades, devem respeito a uma mesma ordem legal vigente, que não se encontra preparada para lidar com tais especificidades.

Portanto, para resguardar o devido respeito às leis e aos princípios constitucionais a que remetem seu uso e violação considera-se os institutos, ora em estudo, similares no sentido de correio, dando à correspondência eletrônica a natureza de correspondência postal, embora com distinções no momento de sua execução, como a maneira de envio ou a propriedade dos meios utilizados nessa tarefa. 


\title{
3 Do monitoramento do correio eletrônico
}

\subsection{Da colisão de direitos}

O uso da internet como meio de comunicação nas relações de trabalho, como dito alhures, simplifica os procedimentos, ao tornar a comunicação mais célere e menos dispendiosa que por qualquer outro meio. Tais vantagens, aliadas `a facilidade de manuseio e `a confiabilidade no envio e recebimento de mensagens, explicam a vasta utilização do instrumento correio eletrônico pelos funcionários dentro da empresa.

Ocorre que, para lidar com essa realidade, certas empresas têm se valido, cada vez mais, de programas de computadores com o intuito de rastrear e interceptar as mensagens eletrônicas enviadas por seus funcionários sem que estes saibam, utilizando-as, por vezes, contra os mesmos, em hipóteses de justificativa para demissões.

Nesse sentido firma-se uma situação complexa, devidamente explicitada por Alessandra Loyola Mistrongue e Felipe de Oliveira Kerstense (2004, p. 310):

\begin{abstract}
se, por um lado, os empregadores servem-se de tais métodos como forma de controle e vigilância dos funcionários, apenas no exercício da função de gestor da relação de emprego; por outro lado, os empregados alegam ofensa aos direitos fundamentais assegurados pela Constituição Federal, principalmente no que toca à tutela da vida privada e à intimidade.
\end{abstract}

Logo, a utilização do email na atividade laborativa tem suscitado repercussão na área jurídica, pela divergência de interesses empregado/empregador, na maioria das vezes. Situação na qual se observa a colisão, basicamente, dos seguintes princípios:

O princípio da propriedade privada, sendo o poder de direção do empregador uma de suas aplicações e os princípios da inviolabilidade da correspondência e da vida privada do empregado (BELMONTE, 2004, p.72).

Se a propriedade do computador capaz de acessar a internet e o correio eletrônico é do empregador, e sendo este detentor da organização da força produtiva e do direito de fiscalizar a correta utilização dos meios colocados à disposição dos empregados para a realização do trabalho para o qual é remunerado, ferirá os direitos à privacidade e ao sigilo de correspondência, fundamentais e constitucionalmente assegurados, ao vasculhar os emails dos empregados? 
À colisão de direitos dá-se o nome de antinomia jurídica, que, para Maria Helena Diniz (2002, p. 83), significa "o conflito entre duas normas, dois princípios, ou de uma norma e um princípio geral de direito em sua aplicação prática a um caso particular". Seria, então, a presença de duas normas conflitantes, sem que se possa saber qual delas deverá ser aplicada ao caso singular.

Canotilho (apud BELMONTE, 2004, p. 83) entende que na colisão de princípios constitucionais não há antinomia e sim dimensões distintas de concretização, sendo sanáveis pela busca de outros critérios, quais sejam:

o do juízo de ponderação ou valores jurídicos fundamentais, em que se aplica a regra da máxima observância e da mínima restrição, de forma a alcançar-se, pelo meio menos lesivo, o menor sacrifício dos direitos envolvidos; e o da dimensão de peso e importância, consistente no peso relativo dos interesses envolvidos, constatando, no caso concreto, qual valor deve ser preservado.

Segundo o ilustre doutrinador português, o juízo de ponderação deve pautar-se em três princípios: o da unidade da Constituição, consistente na interpretação sistemática das normas e princípios; o da concordância prática, obtida por meio da harmonização que permita o melhor equilíbrio possível entre os princípios colidentes, a máxima concretização dos direitos envolvidos e o da proporcionalidade, que objetiva, por meio de balanceamento e estabelecimento de limites, a prevalência de um direito sobre o outro, quando absolutamente necessário para a resolução do conflito.

Os critérios apontados têm o intuito de realizar o direito, afastando as contradições e permitindo a valorização de bens jurídicos em conflito, diante de circunstâncias que justifiquem o procedimento.

A solução da colisão dos direitos em questão leva a uma das seguintes situações: a possibilidade absoluta do monitoramento, a impossibilidade absoluta de fazê-lo e, finalmente, a possibilidade de monitorar observados certos parâmetros ou diante de certas circunstâncias.

\subsection{Do monitoramento}

É muito grande o ônus suportado por uma empresa que, ao fornecer meios aos empregados para facilitar o desempenho de suas atividades, tem observado o 
desvirtuamento da função para a qual a internet é disponibilizada no ambiente de trabalho, o que justifica formas de vigilância sobre o uso dos computadores no ambiente laboral.

As formas de vigilância encaixam-se em três hipóteses, na visão de Alexandre Agra Belmonte (2004, p. 28), quais sejam:

\begin{abstract}
Acesso às informações pessoais armazenadas no computador (facilitada quando se trata de máquinas em rede); Acesso ao conteúdo e registros dos emails enviados e recebidos e web pages visitadas; Acesso ao registro de uso, possibilitando saber como o empregado utiliza o computador, medindo-se tanto a quantidade quanto a qualidade do trabalho realizado.
\end{abstract}

Dentre tais maneiras de monitoramento, o acesso ao conteúdo e registros dos emails enviados e recebidos e às páginas visitadas é a que se perfaz objeto desse estudo.

\title{
3.3 Dos limites de razoabilidade do monitoramento
}

Para o estabelecimento de limites da vigilância patronal sobre a correspondência eletrônica do empregado e a internet, Fragale sustenta que deverá conjugar-se a existência de um regulamento empresarial `a prévia notificação do empregado. Referido doutrinador estabelece três situações possíveis para a regulamentação do uso dos terminais de computador, quais sejam: "a proibição pura e simples de uso; proibição parcial de uso, condicionada a certas restrições e condições; ausência explícita de limitações de uso" (apud BELMONTE, 2004, p. 75).

No que toca à prévia notificação do empregado para a ciência da vigilância, apesar de essencial para o estabelecimento da razoabilidade de monitoramento, pode ser que continue o entrave entre a privacidade e o poder de comando.

Por derradeiro, Fragale, apresenta como bases para a solução do problema os seguintes critérios: "o respeito à dignidade do trabalhador e a adequação entre o procedimento de vigilância e o seu propósito" (apud BELMONTE, p. 76).

Segundo os critérios apontados, sobre o conflito entre os direitos de propriedade do empregador e o direito à intimidade e à privacidade do empregado paira um limite alhures abordado: o da dignidade do trabalhador. Nos dizeres de José Luciano de Castilho Pereira (2004, p. 1030) "é na dignidade de quem trabalha que deve estar endereçado todo o direito do trabalho, que é espécie dos Direitos Humanos". Entretanto, os mencionados 
direitos devem ser exercidos, no âmbito da relação de trabalho, conforme as circunstâncias e necessidades, buscando-se a harmonização das normas ou sua máxima operacionalidade.

Com relação ao segundo critério, a adequação entre o procedimento de vigilância e o seu propósito, busca-se a idéia do que seria razoável em termos de vigilância e o seu propósito, que deve ser previamente indicado. Pois, no entender de Fragale, se a finalidade da vigilância for avaliar a performance do empregado, não poderá, ser utilizada posteriormente com fins disciplinares, e vice e versa. Um circuito televisivo instalado para fins de formação profissional ou treinamento dos empregados, por exemplo, não pode ser utilizado para justificar a dispensa de funcionário (BELMONTE, 2004, p. 76). Sua posição é defendida com as seguintes palavras:

Tal vinculação estaria relacionada ao princípio constitucional do devido processo legal (art. 5ㅇ, LV, CF), que no âmbito da relação de trabalho funcionaria similarmente como 'filtro' da atuação do empregador, especialmente em se tratando da interferência na intimidade do empregado que possa ferir sua dignidade.

Diante do limite de razoabilidade exposto, fica nítido o fato de que o empregado deve ter prévio conhecimento do que The é permitido realizar, sendo necessário, além da notificação prévia, a exposição dos objetivos da vigilância a que esta sendo submetido.

\subsection{Da sistematização dos posicionamentos quanto ao monitoramento}

Diante da análise do monitoramento e dos possíveis limites de razoabilidade para que este aconteça, chega-se à sistematização de certos posicionamentos a respeito da vigilância e seus respectivos fundamentos:

o de quem entende que, com fundamento na propriedade privada, o empregador pode verificar à vontade os emails dos empregados; o de quem acredita que, baseado no direito à intimidade e na vedação decorrente da inviolabilidade das comunicações, o empregador não pode verificar os emails dos empregados e, enfim, o de quem acredita que, resolvendo a colisão entre a propriedade privada e a intimidade por meio do respeito à dignidade do trabalhador, surta duas situações: A) ser possível monitorar o trabalho eletrônico do empregado para a verificação de não estar havendo utilização para fins estranhos ao serviço, desde que o empregador tenha dado prévia ciência ao empregado; B) ser possível estabelecer um padrão razoável de vigilância, de maneira a ser permitida a utilização do correio eletrônico nos intervalos do serviço e ser considerada vedada 
a utilização em serviço somente com prévia comunicação ao empregado da vigilância (BELMONTE, p. 78).

Posicionar-se quanto a um dos critérios arrolados faz-se necessário à completa elaboração do presente estudo, entretanto, para esta tarefa cabe analisar, um pouco mais, cada um deles.

\subsubsection{Da possibilidade irrestrita}

Agarram-se ao fundamento da propriedade privada do empregador e sua responsabilidade perante terceiros, os que prevêem a possibilidade irrestrita de monitoramento de correspondência eletrônica.

Contudo, a fiscalização exaustiva e injustificável do correio eletrônico dos empregados por parte dos empregadores, com fulcro na propriedade privada deve ser considerada condenável, com base na doutrina constitucional, pois o contrato de trabalho não é uma área autônoma e alheia à Constituição. $O$ acesso indiscriminado ao correio eletrônico, vulnera o direito do trabalhador em seu sigilo a comunicações, desrespeitando a dignidade do trabalhador, bem como o Princípio da Função Social da Propriedade, cujo mérito faz-se necessário abordar em poucas palavras.

\subsubsection{Da função social da propriedade}

O art. 5ํ, XXII da Constituição Federal, garante o direito á propriedade. O seguinte inciso, XXIII, dispõe que a propriedade atenderá sua Função Social.

Propriedade é o direito real de usar, gozar, dispor e reaver bem móvel ou imóvel, segundo art. 1.228 , do CC. O $\$ 1$ 을 do referido artigo, preceitua que esse direito deva ser exercido conforme as suas finalidades econômicas e sociais, de modo a permitir o ajuste da conveniência privada ao interesse coletivo, o que nada mais é do que atender à função social.

Para Vladimir da Rocha França (p. 1),

O princípio fundamental da função social da propriedade constitui o alicerce constitucional do regime jurídico-constitucional da propriedade, estando todos os demais princípios e regras constitucionais a ele submetidos, inclusive o princípio da propriedade privada estabelecido no art. 170, II, da Lei Maior. Se o constituinte 


\begin{abstract}
desejasse colocar o princípio da apropriação privada dos bens econômicos como superior ao da função social, deveria tê-lo posto como princípio constitucional fundamental, o que se seria histórica e sociologicamente irreal. Não vemos no art. 5o da Carta Magna uma inserção do princípio da propriedade privada, mas sim da instituição da propriedade, submetida ao princípio da função social da propriedade. Somente se insistirmos numa concepção individualista da propriedade, fulminada pela Constituição e pelos fatos, é possível se admitir que a função social constitua um elemento acessório da propriedade privada. Optamos em colocar a função social da propriedade como princípio superior ao da propriedade privada, já que é justamente aquela o núcleo de sustentação e estabilidade da instituição da propriedade nos dias atuais.
\end{abstract}

Atendendo a Função social da propriedade, o §2 do supracitado artigo, dispõe que são defesos atos que além de não trazer ao proprietário qualquer comodidade ou utilidade, sejam animados pela intenção de prejudicar outrem.

Na mesma acepção, Mara Helena Diniz (2002, p. 733-734), rege que

as limitações ao direito de propriedade têm por fim coibir abusos e impedir prejuízos ao bem estar social, possibilitando, assim, uma utilização socialmente justa e economicamente produtiva, atendendo, a um só tempo, os interesses do proprietário, da sociedade e do Estado, afastados o individualismo, o desperdício e o uso abusivo ou atentatório do domínio.

Portanto, conclui-se que o direito de propriedade deve ser exercido nos limites de sua função social. O fato de o empregador deter a propriedade do equipamento utilizado pelo empregado para a prestação dos serviços, por si só não autoriza o exercício do poder diretivo absoluto com a intervenção no correio eletrônico de seus funcionários, caracterizando-se como abuso o exercício anti-social de um direito, passível a gerar indenização àquele que se sentir lesado.

\title{
3.4.2 Da impossibilidade irrestrita
}

Valem-se da invocação do direito à privacidade, intimidade e inviolabilidade das comunicações, como direitos absolutos, a corrente em defesa da proibição irrestrita da intervenção da correspondência eletrônica nas relações de trabalho.

Ocorre que nenhum direito pode ser exercido sem restrições. É de conhecimento popular que o direito de um termina onde começa o de outro. Diante disso, é sábio dizer que inclusive o direito invocado, direito à intimidade, deve sofrer ajuste, limitação, ou mesmo ceder, quando existir a necessidade de tutelar outro direito igual ou mais relevante, 
conforme as circunstâncias. Trata-se dos princípios do juízo de ponderação e da dimensão de peso e importância, outrora referidos neste trabalho.

Uma vez constatada a divulgação de informação sigilosa, a distribuição de imagens pornográficas por computadores da empresa, o uso indevido da rede em horário de serviço, para fins particulares, o congestionamento da rede, sem motivo aparente, é cabível a possibilidade de monitoramento pelo empregador, tendo em vista que este não pode suportar a perda de produtividade pelo desvio de finalidades dado às máquinas disponibilizadas para o desempenho das funções dentro da empresa.

Assim como o direito da propriedade deve pairar-se sobre certos limites, o direito à intimidade também o deve. Tais direitos não podem ser exercitados se não dentro das características próprias e especiais das relações de trabalho. Deve haver uma harmonização diante da máxima operacionalidade nas circunstâncias que exigirem a sua utilização, pelo princípio da proporcionalidade.

Não pode ser acolhida a tese de que o direito à intimidade impeça a possibilidade de monitoramento patronal dos emails de seus empregados. O que, muito embora, não queira dizer que esse monitoramento seja feito fora de certos limites, sob o fundamento único da propriedade privada.

\subsubsection{Da possibilidade com restrições}

Conciliando critérios das correntes anteriormente expostas e, com isso, os princípios outrora mostrados colidentes, chega-se a uma posição intermediária: de possibilidade de monitoramento do correio eletrônico, não somente baseada no fato da propriedade dos instrumentos de trabalho, mas como decorrência de circunstâncias específicas.

Diante disso, chega-se à oportunidade de se abordar as duas modalidades de correspondência eletrônica: o email corporativo e o email pessoal.

\subsubsection{Do correio eletrônico corporativo}

Entende, a maior parte da doutrina, serem, o correio postal e o eletrônico, institutos similares no sentido de correio, porém com modo de execução diferente. Todavia, 
quer com a natureza de carta ou natureza diversa, pode a mensagem eletrônica ser entendida como objeto de correspondência, passível de proteção direta pelo sigilo das comunicações e, indiretamente, pelo direito à intimidade.

Entretanto, admitida a hipótese de equivalência à correspondência postal, a natureza do correio eletrônico corporativo difere ostensivamente da conta eletrônica pessoal. Aquele seria o email institucional, proporcionado pela empresa, individualizado em nome do empregado e acessado por meio de senha, que não encontra abrigo nas disposições constitucionais que resguardam o sigilo da correspondência, motivo pelo qual a elas não se sujeita.

Ana Amélia Menna Barreto de Castro Ferreira (2003, p. 16) afirma que

\begin{abstract}
Uma vez que a informação contida nas mensagens corporativas é de natureza comercial e integra o ambiente privado da companhia, o sigilo que merece proteção se opera em favor do proprietário da ferramenta de trabalho e se dirige às informações sigilosas da empresa. Em se tratando de conta de correio eletrônico pessoal, a proteção à privacidade advém da natureza do ambiente confidencial e íntimo de seu titular.
\end{abstract}

Ao disponibilizar seus recursos tecnológicos ao funcionário, o empregador coloca à disposição uma ferramenta de trabalho com destinação exclusiva ao desenvolvimento das atividades a que foi contratado e durante a jornada pactuada, com a finalidade precípua de facilitar e agilizar a comunicação interna e externa, de assuntos de caráter estritamente comercial vinculados à sua atividade. Essa ferramenta trafega através da rede privada de computadores da empresa, suportando o empregador, na qualidade de proprietário dos equipamentos e titular da caixa postal, com os custos do registro e outros relativos à prestação dos serviços de provimento de acesso e conexão a internet.

Pode-se inferir que o correio eletrônico corporativo destina-se, especificamente, ao tráfego de informações comerciais, motivo pelo qual não comporta proteção de confidencialidade em relação ao empregado. As características específicas que envolvem a mensagem eletrônica corporativa não encontram respaldo para o enquadramento no preceito constitucional garantidor da inviolabilidade da correspondência, nem tão somente da intimidade e vida privada, o que confere ao empregador o controle material, ou seja, do conteúdo das mensagens, independentemente da chamada cláusula de invasão de 
privacidade, que vem a ser uma cláusula coletiva, cujo mérito seja eliminar o questionamento da licitude do rastreamento quanto ao e-mail corporativo.

Mediante negociação coletiva, os próprios empregados expressamente, ou através do compromisso de utilização dos recursos somente para o exercício de sua atividade, permitem o procedimento de controle. Configura-se lícita a cláusula de invasão de privacidade, reguladora do uso dos equipamentos. Entretanto, adverte-se ao fato de que só terá validade desde que proveniente de negociação coletiva, observada a possibilidade de recusa, não sendo vinculada à adesão nos contratos particulares, hipótese em que poderá constatar-se a coação.

Portanto, caracterizado como ferramenta de trabalho, com a finalidade de ser utilizado no serviço e em prol do serviço, o email coorporativo está sujeito à vigilância e controle do empregador.

\subsubsection{Do correio eletrônico pessoal}

Na conta de correio eletrônico pessoal ou particular é a pessoa física quem contrata os serviços de um provedor de acesso, com a finalidade de criar um email pessoal. Esse email insere-se em ambiente de privacidade absoluta de seu titular, uma vez que as informações trafegadas são de natureza pessoal e confidencial, para tanto, se sujeitando à proteção das garantias constitucionais da intimidade e privacidade, bem como da inviolabilidade das comunicações.

Entretanto, utilizado no trabalho por meio de recursos do empregador, deve haver, na realização do poder diretivo, um monitoramento meramente formal. O empregador pode utilizar-se do bloqueio (indiretamente) ou proibição (diretamente) do acesso em horário de serviço ou a utilização por intermédio de seu equipamento. Contudo, o controle material, sobre o conteúdo das mensagens, não poderá ser exercido (BELMONTE, 2004, p.79).

O acesso ao conteúdo das mensagens eletrônicas somente se dará por prévia autorização, judicial ou do próprio empregado. Qualquer intromissão não autorizada será considerada abusiva, violando à intimidade e o sigilo das correspondências, direitos fundamentais do trabalhador, ensejando eventuais reparações de cunho moral e material. 
Vale lembrar no tocante à cláusula de invasão de privacidade que, quanto ao email pessoal, ela é descabida, uma vez tratar-se de conteúdo, em princípio inviolável, cujo acesso dar-se á, unicamente, por exceção.

Em casos, por exemplo, em que ocorra desconfiança de abuso do servidor patronal ou de utilização indevida pelo empregado, o empregador poderá postular autorização judicial para a intervenção no email particular, ou, então, assumir a responsabilidade do rastreamento material se entender estar diante de estado de necessidade que justifique o rastreamento.

Cabe ao trabalho tecer algumas palavras a respeito da autorização judicial para o rastreamento.

\subsection{Da autorização judicial para intervenção e da prova judicial}

Preceitua a Constituição Federal, art. 5ㅇ, XII, serem invioláveis o sigilo das correspondências e das comunicações.

Eis que a elaboração da Lei 9296 de 1996 teve a intenção de regulamentar a parte final do mencionado inciso, no que toca à interceptação de comunicações, devido ao fato da interpretação usual aplicar a quebra do sigilo somente às comunicações telefônicas.

$\mathrm{O}$ art. 1 o da referida lei reza que a interceptação de comunicações telefônicas, de qualquer natureza, para prova em investigação criminal e em instrução processual penal, observará o disposto em Lei e dependerá de ordem do juiz competente da ação principal, sob segredo de justiça. Consagra, o parágrafo único deste artigo, que o disposto aplicar-se-á à interceptação do fluxo de comunicações em sistemas de informática e telemática, diante do que se constata que a autorização judicial é cabível, também para o caso em discussão, de correspondências eletrônicas.

Verificada a vedação à interceptação das comunicações, questão que se faz de grande repercussão é a respeito da utilização da prova obtida com transgressão ao direito à intimidade. Sendo obtida de forma ilícita, contrariamente às determinações do direito material, a prova proveniente de intervenção não autorizada do correio eletrônico pessoal terá sua utilização proibida. É o que reza a Constituição Federal art. 5o, LVI: "são inadmissíveis, no processo, as provas obtidas por meios ilícitos". 
Todavia, em muitas situações, negar a utilização da prova obtida com invasão da intimidade alheia seria negar o direito de comprovar fato tão repudiado pelo direito quanto à transgressão do respeito à intimidade.

Depara-se, mais uma vez, com a colisão de direitos, uma antinomia jurídica a ser sanada, conforme já exposto neste trabalho, com o juízo de ponderação, de forma a alcançar-se o mínimo sacrifício dos direitos envolvidos e obter-se a máxima observância, regendo-se pelos princípios, anteriormente elucidados. São eles: o da unidade da Constituição, o da concordância prática e o da proporcionalidade. Não sendo suficientes para solucionar a questão, valer-se-á do critério da dimensão de peso e importância, buscando valores e interesses, diante das condições fáticas e jurídicas.

Discorrendo nesse estudo, afastando a hipótese de estado de necessidade, terá como o empregador provar que seu funcionário envia e recebe fotos pornográficas, mensagens de cunho depreciativo quanto aos superiores hierárquicos, realiza negócios com empresas concorrentes, enviando a elas informações sigilosas com base em prova obtida de maneira ilícita? Abordando, ainda, uma outra questão: seriam atitudes passíveis de ensejar demissão por justa causa?

Sob o aspecto da utilização da prova terão que ser avaliados os casos e implicações em questão, se o prejuízo suportado pelo empregador justificaria sua intromissão abusiva, segundo os critério razoáveis apontados para a colisão de direitos.

Em relação à demissão por justa causa, é sabido que, subsumindo-se certa conduta às alíneas do art. 482 da CLT, tipificada estaria para a caracterização de motivo justo para a demissão por parte do empregador. Assim sendo, analisando a alínea " $b$ " do mesmo artigo, "Incontinência de conduta ou mau procedimento", depara-se com um termo aberto capaz de abranger comportamentos extremamente diferenciados.

No conceito de Maurício Godinho Delgado (2006, p. 1192), o mau procedimento, trata-se de uma conduta culposa do empregado que atinja a moral, sob o ponto de vista geral, excluído o sexual, prejudicando o ambiente laborativo ou as obrigações contratuais.

Logo, considera-se, que além de ampla, a possibilidade de caracterização da justa causa, consagra-se em critério de análise específica, uma vez que para construir sua argumentação e decisão, o julgador estará adstrito às particularidades de cada caso e, de certo, a sua análise subjetiva. 


\subsection{Da reparação de danos: possibilidade de indenização e ressarcimento}

O uso indevido dos equipamentos colocados à disposição pelos empregadores para o desempenho das atividades de seus empregados pode suscitar, em muitas vezes, sérios prejuízos à empresa. É devido a esse fato que, por todo o exposto, é plenamente justificável o monitoramento patronal do correio eletrônico corporativo de seus funcionários, bem como, o monitoramento, em delimitadas hipóteses, do correio eletrônico pessoal dos mesmos.

Entretanto, podem ocorrer intromissões discricionárias e abusivas nos e-mails dos empregados com o acesso à mensagens de cunho extremamente pessoais e confidenciais que os exponham à situações constrangedoras. É necessário mencionar que, para estes casos, é direito do empregado ser indenizado pela ingerência, sem justificativas plausíveis, do empregador à esfera de sua intimidade, constitucionalmente assegurada e já exaustivamente comentada no presente trabalho.

O pedido de ressarcimento advindo de lesões cometidas a tais direitos é, portanto, direito do trabalhador, assim como, da empresa prejudicada economicamente devido ao uso indevido das tecnologias de comunicação e informação pelos seus empregados. Além da decretação da resolução culposa do contrato, por mau procedimento, a empresa fará jus a indenização pelos eventuais prejuízos morais e patrimoniais propiciados pelo empregado.

O pagamento da indenização pela reparação moral e/ou patrimonial será arbitrado de tal modo que seja capaz de desestimular as atitudes lesivas, ao empregado ou a empresa, e que satisfaça a perda do lesionado. Faz-se tarefa árdua aferir valores para reparações de cunho moral, escapando-se das intenções de abordagem do presente trabalho. Mencionase, por ora, a necessidade de ser comprovada a relação de causalidade entre o dano e a ação que o provocou.

Vale lembrar que a reparação dos danos pode ocorrer no decurso do contrato, independente de resolução contratual.

Logo, Alexandre Agra Belmonte, afirma que é dever da empresa dar ciência aos empregados das condutas que não são admitidas pela empresa; das eventuais limitações no uso dos equipamentos eletrônicos e penalidades decorrentes da transgressão; bem como conscientizar seus empregados, de forma a evitar a prática de atos que possam lhe causar 
prejuízos. Sendo assim, mesmo se responsabilizando pelos atos junto a terceiros, a empresa poderá ter a possibilidade de ressarcimento pelo empregado, em certas situações.

\subsection{Do uso social do correio eletrônico}

O empregado tem direito à comunicação externa durante o expediente de trabalho. Todavia, dentro de limites que não interfiram na sua produção, cabendo ao empregador fixar tais limites.

Considerando o uso dos computadores no ambiente de trabalho, o empregador deve conscientizar os empregados de que o computador é uma ferramenta de trabalho e não um instrumento para comunicações pessoais, para tanto, pode proibir ou estabelecer limites para a utilização do correio eletrônico e da internet para fins pessoais. Eis o que Mário Antônio Lobato de Paiva denomina uso social do e-mail (apud BELMONTE, 2004, p.90).

Logo, concomitante com a possibilidade de ser efetuado o monitoramento formal e/ou material, conforme o tipo de correspondência, pessoal ou corporativa, deve haver expresso regulamento proibindo ou autorizando o uso moderado de email particular ou corporativo para fins pessoais no ambiente laboral. Também informando que na ocorrência do desrespeito à proibição ou abuso de utilização, serão impostas as penas disciplinares que a reiteração, intensidade da falta e circunstâncias do caso recomendarem, desde a advertência à resolução contratual por justa causa.

Por derradeiro, Luis Alberto de Vargas (apud ROCHA, 2004, p. 142) aponta sugestões de premissas para o monitoramento do email pelo empregados. Seriam elas:

I. a existência de uma política transparente e proporcionada que faça o empregado consciente do caráter não sigiloso de suas comunicações no local de trabalho, configurando-se na melhor maneira de conciliar as exigências de segurança com um ambiente de trabalho mais agradável e produtivo.

II. Parece ser essencial que a empresa advirta aos empregados de que todas as mensagens, de qualquer tipo, inclusive as protegidas por senhas, estão potencialmente disponíveis para o conhecimento da empresa.

III. O monitoramento do correio recebido pelo empregado é, em qualquer hipótese, uma violação da privacidade de terceiros que, provavelmente, desconheciam as normas empresariais e que o destinatário não tinha privacidade em suas comunicações. 
IV. O monitoramento constante e sem clara finalidade específica de todas as comunicações não é justificável.

V. O controle por parte da empresa do tempo e dos endereços eletrônicos navegados na internet pelo empregado é razoável, sob o argumento de que a utilização do equipamento empresarial deva ser produtiva.

Deste modo, devido à precariedade de normas jurídicas que disciplinem o uso e o monitoramento de correspondência eletrônica no ambiente de trabalho, tais premissas poderão ser utilizadas para a construção de uma política empresarial, cujo procedimento seja adotado com a anoieeuência de seus empregados, para evitar litígios por falta de esclarecimento prévio e que acabem sem justa resolução.

Portanto, é legítimo e fundamental o direito da empresa de proteger seus ativos de informações e processamento, delineando normas para a utilização racional dos equipamentos, sendo necessário o aviso formal aos empregados de sua existência e, recomendável à empresa, de último plano, que o empregado seja lembrado desta política cada vez que ele se conectar ao sistema de informática da empresa, através de mensagem eletrônica que, além de informar exija a confirmação de que o empregado recebeu a mensagem, entendeu o aviso e tem conhecimento da política da empresa e está de acordo.

\section{Conclusão}

Do exame do tema, conclui-se que há carência de legislação pertinente às discussões a respeito da possibilidade de monitoramento dos correios eletrônicos dos empregados, no ambiente de trabalho. Salienta-se a necessidade de movimentação do aparato legislativo no sentido de acompanhar o desenvolvimento tecnológico, dirimindo os novos conflitos surgidos na esfera de emprego.

Conquanto inexistente uma política precisa para a utilização da correspondência eletrônica, convém, equipara-la à correspondência postal, sem desconsiderar suas peculiaridades, em certos pontos, para considerá-la passível de proteção dos Princípios Constitucionais da inviolabilidade das comunicações e do direito à intimidade e privacidade. Constituindo, assim, ilegal a intervenção patronal.

Entretanto, grande é a preocupação com o manuseio indevido do sistema operacional, instalado e colocado à disposição dos funcionários às expensas do empregador, 
o que tem levado ao controle do uso dos computadores por parte deste, seja de maneira formal, programas utilizados e páginas visitadas através da rede internet, seja de maneira material, acesso ao conteúdo das correspondências enviadas e recebidas.

É direito e dever do empregador, conferido pela propriedade privada dos meios e pelo poder diretivo das atividades, zelar pela devida aplicação dos equipamentos disponibilizados aos funcionários com vistas à agilidade e incremento de sua produção. Todavia, desde que o exercício desse direito não interfira na intimidade e privacidade do monitorado e respeite a Função Social da Propriedade.

Diante da colisão de direitos observada, foram apresentadas distintas posições: da possibilidade, da impossibilidade e da possibilidade de monitoramento das correspondências com restrições.

Ao filiar-se ao último posicionamento, o trabalho explorou um padrão razoável de vigilância: o respeito à dignidade do trabalhador e a adequação entre o procedimento de vigilância e o seu propósito. Distinguiu, ainda, duas modalidades de mensagens eletrônicas: a coorporativa, ferramenta de trabalho fornecida pela empresa e utilizada em nome dela, cujo conteúdo é passível de vigilância, e a pessoal, espaço de privacidade absoluta de seu titular, objeto de monitoramento em situações excepcionais.

O presente estudo explicita, com o objetivo de evitar conflitos judiciais, a necessidade de adoção de uma política com diretrizes claras e objetivas quanto à utilização da internet e do correio eletrônico no ambiente de trabalho. Sobremaneira importante elucidar a consideração de três pontos principais para a elaboração dessa política: a prévia anuência do empregado quanto à sua aplicação; esclarecimento ao empregado da não incidência de proteção de privacidade do correio eletrônico corporativo; estabelecimento de regras por meio de diretivas precisas que descrevam as circunstâncias nas quais os correios eletrônicos dos empregados serão controlados, de maneira a afastar qualquer dúvida quanto à existência de uma esfera privada no local de trabalho.

\section{Referências}

ARAUJO, Eneida Melo Correia de. As relações de trabalho: uma perspectiva democrática. São Paulo: Ltr, 2003. 
BELMONTE, Alexandre Agra. O monitoramento da correspondência eletrônica nas relações de trabalho. São Paulo: Ltr, 2004.

DELGADO, Maurício Godinho. Curso de Direito do Trabalho. 5. ed. São Paulo; Ltr, 2006.

DINIZ, Maria Helena. Curso de Direito Civil Brasileiro: Teoria Geral do Direito Civil. 19. ed. rev de acordo com o novo Código Civil. São Paulo: Saraiva, 2002. v. 1.

FERREIRA, Ana Amélia Menna Barreto de Castro. Correio Eletrônico Corporativo: Aspectos jurídicos. Revista de Direito do Trabalho, v. 29, n. 110, abr./jun. 2003.

FRANÇA, Vladimir da Rocha. Perfil Constitucional da Função Social da Propriedade. Disponível em: < http://jus2.uol.com.br/doutrina/texto.asp?id=676 > Acesso em: 20 abr. 2007.

MISTRONGUE, Alessandra Loyola. KERSTEN, Felipe de Oliveira. Invasão de privacidade: a violação de emails nas relações de trabalho à luz da ordem Jurídico-Constitucional Brasileira. Revista Ltr, São Paulo, v. 68, n. 03, mar. 2004.

PAIVA, Mário Antônio Lobato de Paiva. O monitoramento do correio eletrônico no ambiente de trabalho. Direito e Tecnologia da informação . R. CEJ, Brasília, n. 19, p 24-39, out./dez.2002.

PEREIRA, José Luciano de Castilho. Correspondência Eletrônica nas Relações de Trabalho. Revista Ltr, São Paulo, v. 68, n. 09, set. 2004.

ROCHA, Marcelo Oliveira. Do monitoramento de emails no ambiente de trabalho. 1. ed. São Paulo: Paulistanajur LTDA, 2004.

SILVA, Antônio Álvares da. Flexibilização das relações de trabalho. São Paulo: Ltr, 2002. 